\title{
Correction to: Australian hospital staff perceptions of barriers and enablers of domestic and family violence screening and response
}

Debra K. Creedy ${ }^{1}$, Kathleen Baird ${ }^{1,2,3^{*}}$, Kerri Gillespie ${ }^{2}$ and Grace Branjerdporn ${ }^{2}$

Correction to: BMC Health Serv Res 21, 1121 (2021).

https://doi.org/10.1186/s12913-021-07083-y

Following publication of the original article

[1], the authors identified an error in the family name of the author Grace Branjerdporn.

The incorrect author names are: Grace Brandjerdporn.

The correct author names are: Grace Branjerdporn.

The author group has been updated above and the original article [1] has been corrected.

\section{Author details \\ ${ }^{1}$ Transforming Maternity Care Collaborative, School of Nursing and Midwifery, Griffith University, University Drive, Meadowbrook, Queensland 4131, Australia. ${ }^{2}$ Gold Coast University Hospital, Parklands Drive, Meadowbrook 4215, Australia. ${ }^{3}$ Centre for Midwifery, Child and Family Health, School of Nursing and Midwifery, Faculty of Health, University of Technology Sydney, Ultimo 2007, Australia.}

Published online: 08 November 2021

\section{Reference}

1. Creedy D, et al. Australian hospital staff perceptions of barriers and enablers of domestic and family violence screening and response. BMC Health Serv Res. 2021;21:1121.

\footnotetext{
The original article can be found online at https://doi.org/10.1186/s12913021-07083-y.

* Correspondence: Kathleen.Baird@uts.edu.au

${ }^{1}$ Transforming Maternity Care Collaborative, School of Nursing and Midwifery, Griffith University, University Drive, Meadowbrook, Queensland 4131, Australia

${ }^{2}$ Gold Coast University Hospital, Parklands Drive, Meadowbrook 4215, Australia
}

(c) The Author(s). 2021 Open Access This article is licensed under a Creative Commons Attribution 4.0 International License, which permits use, sharing, adaptation, distribution and reproduction in any medium or format, as long as you give appropriate credit to the original author(s) and the source, provide a link to the Creative Commons licence, and indicate if changes were made. The images or other third party material in this article are included in the article's Creative Commons licence, unless indicated otherwise in a credit line to the material. If material is not included in the article's Creative Commons licence and your intended use is not permitted by statutory regulation or exceeds the permitted use, you will need to obtain permission directly from the copyright holder. To view a copy of this licence, visit http://creativecommons.org/licenses/by/4.0/. The Creative Commons Public Domain Dedication waiver (http://creativecommons.org/publicdomain/zero/1.0/) applies to the data made available in this article, unless otherwise stated in a credit line to the data. 